\title{
Factors Influencing Use of Monsoonsim Business Simulation by UTM Undergraduate Students
}

\author{
Shafudin Mohd Yatim (Corresponding author) \\ Senior Lecturer, Department of Business Administration \\ Faculty of Management, Universiti Teknologi Malaysia, Johor Bahru \\ PhD Candidate, Asia E University, Kuala Lumpur, Malaysia \\ E-mail:m-safudi@utm.my; M70101170009@aeu.edu.my \\ Chin Fei Goh \\ Senior Lecturer, Department of Business Administration \\ Faculty of Management, Universiti Teknologi Malaysia, Johor Bahru \\ E-mail: gcfei@utm.my \\ Raihanatul Zahirah Mohamad \\ Final-year Technology Management Student, Faculty of Management \\ Universiti Teknologi Malaysia, Johor Bahru, Malaysia \\ Email: zraihanatu129@gmail.com
}

Received: April 27, 2018 Accepted: May 27, 2018 Published: June 5, 2018

doi:10.5296/ijld.v8i2.13073ＵRL: https://doi.org/10.5296/ijld.v8i2.13073

\begin{abstract}
The study was conducted to investigate the factors that influenced the use of MonsoonSIM business simulation by the undergraduate students of Universiti Teknologi Malaysia (UTM). The objectives of this study were to evaluate the (i) relationship between perceived usefulness, perceived ease of use, and perceived enjoyment towards attitude to use MonsoonSIM, (ii) relationship between perceived usefulness, perceived enjoyment, and attitude to use towards the behavioral intention to use MonsoonSIM (iii) strongest determinants that influenced the students' attitude to use MonsoonSIM. Two hundred and sixty UTM undergraduate students answered this e-questionnaire. Descriptive and inferential analyses were used to evaluate the data. The results of this study showed all the relationships were positively correlated, and that perceived enjoyment was the most significant factor influencing the students' attitude to use MonsoonSIM. In conclusion, there is a higher possibility for the technology to be used by the users if it includes perceived usefulness,
\end{abstract}


perceived ease of use, and perceived enjoyment.

Keywords: Technology acceptance model, business simulation game, MonsoonSIM

\section{Introduction}

\subsection{Background of Study}

Wawer et al. (2010) claimed that business simulation games are one of the effective ways to learn the management of business processes in modern enterprises. Business simulation games are becoming popular tool in education because there are many beneficial skills that can be learned by the participants, such as active individual engagement, teamwork, strategic and analytical thinking, as well as communication.

Nowadays, many technologies have been developed in order to change the users' lives for the better. All industries are constantly developing new technologies to improve the performance of the users. It is a waste if the new technology is not accepted by the users. Therefore, it is necessary for the innovators or marketers of the technology to know the factors that motivate the users to use that particular technology. Thus, to improve the understanding of the factors that influenced the students' usage of business simulation games, this study has adopted the technology acceptance model (TAM) as the theoretical research framework.

\subsection{Problem Statement}

There are insufficient studies on the factors that influence the users' usage of business simulation games as an educational tool, especially in Malaysia (Al-Adwan et al., 2013; Cronan \& Douglas, 2012; Tao et al., 2009). This is because these simulations are new in the Malaysian higher education environment. As stated by Tao et al. (2009), simulation games have become popular tools for informal learning because this generation uses many technologies in their daily lives. For example, in Malaysia, e-learning has long been accepted and used by students. Thus, this study was conducted to fill in the knowledge gap by elucidating the factors that influenced the students' usage of business simulation games.

Other than that, the Technology Acceptance Model (TAM) framework has been utilised in various fields such as WebCT (Ngai et al., 2007), mobile commerce (Wu \& Wang, 2005), online banking (Pikkarainen et al., 2004), e-learning (Al-Adwan et al., 2013; Roca et al., 2006), and others. The TAM framework has also been utilised, albeit in a limited manner, in business simulation games (Tao et al., 2009; Tao et al., 2011). In addition, previous studies on business simulation games have used different types of simulations, which made the findings inconclusive. Thus, in this study, MonsoonSIM was chosen because this type of enterprise resource planning (ERP) simulation was recently introduced to the market. Hence, this research could directly address the knowledge gap in previous studies by using a different type of business simulation game.

\subsection{Purpose of Study}

The purpose of this study was to determine the factors that influenced the Universiti Teknologi Malaysia undergraduate students to use and accept a new type of business 
simulation game (MonsoonSIM) via the Technology Acceptance Model (TAM).

\subsection{Research Objective}

1) To investigate the relationship between perceived usefulness and attitude to use MonsoonSIM.

2) To identify the relationship between perceived usefulness and behavioral intention to use MonsoonSIM.

3) To investigate the relationship between perceived ease of use and attitude to use MonsoonSIM.

4) To identify the relationship between perceived enjoyment and attitude to use MonsoonSIM.

5) To investigate the relationship between perceived enjoyment and behavioral intention to use MonsoonSIM.

6) To identify the relationship between attitude to use MonsoonSIM and behavioral intention to use MonsoonSIM.

7) To determine the elements of the technology acceptance model that had the strongest influence on the students' attitude to use MonsoonSIM.

\section{Literature Review}

\subsection{Technology Acceptance Model (TAM)}

Davis originally developed the TAM in 1986. This model has been built on the theoretical model of human behavior (Fishbein, 1967; Fishbein \& Ajzen, 1975), or the Theory of Reasoned Action (TRA). The TAM has been cited more than 700 times (Tao et al., 2009) and is widely used in various studies in fields like WebCT (Ngai et al., 2007), mobile commerce (Wu and Wang, 2005), online banking (Pikkarainen et al., 2004), e-learning (Roca et al., 2006), and many others. This model can help the innovators of technology to understand the factors that influence the users' acceptance of a newly-developed technology. The TAM model consists of four specific factors, which include perceived usefulness and perceived ease of use. These two factors have an impact on attitude to use. Subsequently, attitude to use has an impact on behavioral intention to use.

\subsubsection{Perceived Usefulness}

Perceived usefulness is the extent to which an individual is convinced to use a particular system that would increase his or her job performance (Davis et al., 1989). Even though new technologies have been developed, the customers are unwilling to believe in and use these, especially technologies that have not been well-established. In several studies, perceived usefulness was found to be significant determinant of user attitudes (Ngai et al., 2007; Park, 2009). Hence, this study has investigated the relationship between perceived usefulness and attitude to use. Apart from that, Davis et al. (1989) believed that the feelings - be it negative or positive - that arose during the intention to use the system would motivate people to intend 
to continue using the system if the system increased their job performance. Thus, this study has investigated the relationship between perceived usefulness and behavioral intention to use.

\subsubsection{Perceived Ease of Use}

Perceived ease of use is the extent to which an individual thinks and believes that less physical and mental effort is needed to use a particular system (Davis et al., 1989). Perceived ease of use significantly influences the acceptance of the users towards the technology (Al-Adwan et al., 2013; Ngai et al., 2007). Usually, when a system is easy to use, people will view it in a more positive way. Therefore, this study was aimed to contribute to the findings by determining the influence of perceived ease of use on the users' attitude to use MonsoonSIM.

\subsubsection{Attitude Toward Use}

Attitude toward use is an individual's evaluative judgment of the target behavior in terms of certain dimensions. For example, good versus bad, harmful versus beneficial, pleasant versus unpleasant, etc. (Holden \& Karsh, 2010). Perceived usefulness and perceived ease of use are the two determinants of attitude toward use, which in turn affects the behavioral intention to use. Hence, this study has reviewed the relationship between attitude to use and behavioral intention to use.

\subsubsection{Behavioral Intention}

Behavioral intention is an individual's drive or willingness to exert effort to perform the target behavior (Holden \& Karsh, 2010). This can be translated into the degree of acceptance of the technology by the user. In this study, several questions in the questionnaire have assessed whether the users had an intention to use the technology or otherwise.

\subsubsection{Perceived Enjoyment}

According to Lee et al. (2005), the factors that were related to the processes of human and social change should be incorporated into the TAM. This would provide better explanations about the factors of IT acceptance. Intrinsic motivation implies that an activity is interesting and, in some way, satisfying. Therefore, it is related to perceived enjoyment, whose concept is that an activity is enjoyable in its own right (Lee et al., 2005). This factor was included in studies like Chang et al. (2003) and Tao et al. (2009), whereby fun and interest were some of the elements that have been evaluated. Other than these two studies, Wawer et al. (2010) stated that simulation games could be considered to be one of the most interesting forms of education. This was proven when almost half of the respondents in the study stated that the game was a form of entertainment. Therefore, in this study, perceived enjoyment was one the factors that had an influence on the users' attitudes. Another relationship is that between perceived enjoyment and behavioral intention to use. As per Davis et al. (1992), perceived enjoyment will give another perspective that has a significant result against the intention to use that are not accounted by the perceived usefulness. Thus, this study has looked at the relationship between perceived enjoyment and behavioral intention to use. 


\section{Macrothink}

\subsection{Business Simulation Games}

Business simulation games are games that educate or train the player to manage business activities and make effective decisions in a simulated environment. According to Wawer et al. (2010), business simulation games are one of the effective ways to improve the know-how in the management of business processes in modern enterprises. There are two types of users of business simulation games, which are business users and students (Faria, 1998; Tao et al., 2009; Wawer et al., 2010). According to Faria (1998), companies that use business simulation games as training tools were large companies. Other users that have been commonly and widely investigated are students as they can enhance numerous skills such as individual engagement, teamwork, as well as strategic and analytical thinking. In this research, the users were the students. Business simulation games are considered as one of the contemporary methods of education. This is because they convey knowledge in a practical way; they also increasingly imitate real-world situations when they becoming more complex business simulation games (Wawer et al., 2010).

\subsection{Proposed Research Model}

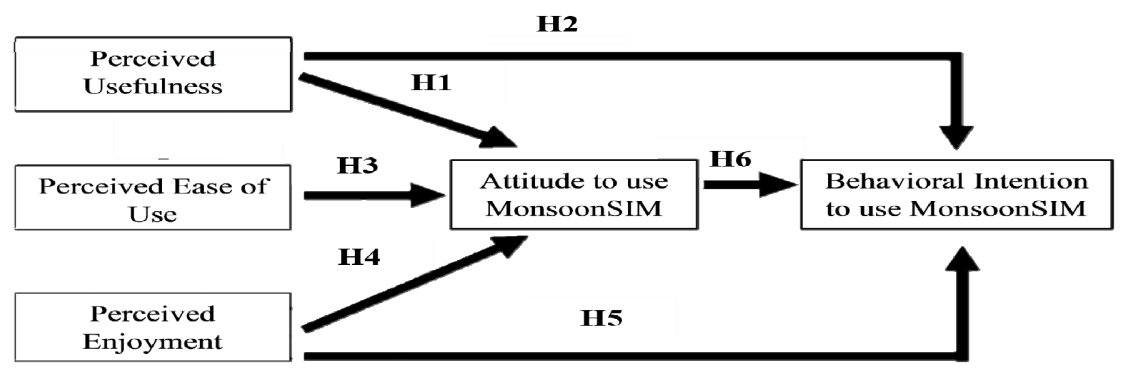

Figure 1. Proposed theoretical research model

\section{Methodology}

\subsection{Research Design}

A deductive approach was used in this study. Hence, this study employed a quantitative approach. An online questionnaire was used to collect the data, as the questionnaire was suitable for large-scale surveys. This study was a cross-sectional study because the data was collected just once. Lastly, the data were descriptively and inferentially analysed.

\subsection{Population and Sampling}

This study was conducted at Universiti Teknologi Malaysia (UTM) with an estimated total population of 800 MonsoonSIM users. The reason for choosing UTM students as the population for this study was that UTM was the first public university in Malaysia to subscribe to MonsoonSIM server. Hence, UTM students have had more experience in playing and using MonsoonSIM. In this study, the sample size was 260, which was determined by using the formula of Krejcie and Morgan (1970). Systematic sampling was conducted to select the respondents. 


\section{Macrothink}

\subsection{Data Analysis}

\subsubsection{Descriptive Analysis}

Descriptive analysis was employed to measure the percentage of each item in the first section of the questionnaire. Mean analysis was employed in the second section of the questionnaire.

\subsubsection{Inferential Analysis}

Inferential analysis was employed to measure the variables in the research model. Two types of inferential analysis were used, which were Pearson correlation and multiple linear regressions. According to Kumar et al. (2013), Pearson correlation is used to measure the degree of linear association between two variables, while multiple linear regressions are used to analyse the relationship between a single dependent variable with more than one independent variable.

\subsection{Research Instrument}

This study used an e-questionnaire to obtain information from the respondents. Items in the questionnaire of this study were adapted from previous researches. In the first section of questionnaire, the respondents filled in their demographic information. In the second section, the respondents answered questions relating to the proposed model of this study. All the items in this section were measured using a five-point Likert scale which ranged from strongly disagree (1) to strongly agree (5). The items are listed in Table 1.

Table 1. The items used in the questionnaire

\begin{tabular}{ll}
\hline SECTION 1: Demographic Background \\
\hline Item & Question \\
1 & Gender: Male / Female \\
2 & Faculty: FKM/ FKE/ FC/ FM/ FGHT/ FS/ FAB/ FBME/ Other \\
3 & Programme of Study: SHAD/ SHAC/ SHAF/ SKEE/ SKEM/ Other \\
4 & Year of Study: $1^{\text {st }}$ year/ $2^{\text {nd }}$ year $/ 3^{\text {rd }}$ year $/ 4^{\text {th }}$ year/ $5^{\text {th }}$ year \\
5 & Frequency of playing MonsoonSIM: Once/ $2-5 / 5-10 /$ more than 10
\end{tabular}

\section{SECTION 2}

\begin{tabular}{llllll}
\hline Item & Factor & Question & & \multicolumn{2}{l}{ Literature Based } \\
\hline PU 1 & & $\begin{array}{l}\text { Using MonsoonSIM improves my learning } \\
\text { performance }\end{array}$ & $\begin{array}{l}\text { (Venkatesh } \\
\text { Davis, 2000) }\end{array}$ & and \\
PU 2 & $\begin{array}{l}\text { Perceived } \\
\text { Usefulness }\end{array}$ & $\begin{array}{l}\text { Having MonsoonSIM in the curriculum enables me } \\
\text { to learn more efficiently } \\
\text { (Ngai et al., 2007) }\end{array}$ \\
PU 3 & & I believe MonsoonSIM contents are useful & (Liaw, 2008) \\
\hline
\end{tabular}




\begin{tabular}{|c|c|c|c|}
\hline PEOU 1 & & $\begin{array}{l}\text { Interacting with MonsoonSIM does not require a lot } \\
\text { of my mental effort }\end{array}$ & $\begin{array}{l}\text { (Venkatesh and } \\
\text { Davis, 2000) }\end{array}$ \\
\hline PEOU 2 & $\begin{array}{l}\text { Perceived } \\
\text { Ease of Use }\end{array}$ & $\begin{array}{l}\text { Learning to operate a MonsoonSIM system is easy } \\
\text { for me. }\end{array}$ & (Ngai et al., 2007) \\
\hline PEOU 3 & & It will be difficult to learn how to use MonsoonSIM & (Lee et al., 2005) \\
\hline PEOU 4 & & Overall, I believe that MonsoonSIM is easy to use & (Ngai et al., 2007) \\
\hline $\begin{array}{l}\text { PENJMT } \\
1\end{array}$ & & Time flies when I use MonsoonSIM & \\
\hline $\begin{array}{l}\text { PENJMT } \\
2\end{array}$ & Enjoyment & It is interesting to use MonsoonSIM & (Tao et al., 2009) \\
\hline $\begin{array}{l}\text { PENJMT } \\
3\end{array}$ & & $\begin{array}{l}\text { I feel like exploring more information when I use } \\
\text { MonsoonSIM }\end{array}$ & \\
\hline $\begin{array}{l}\text { PENJMT } \\
4\end{array}$ & & I would have fun using MonsoonSIM & (Lee et al., 2005) \\
\hline ATU 1 & & Using MonsoonSIM is a good idea & (Ngai et al., 2007) \\
\hline ATU 2 & $\begin{array}{l}\text { Attitude To } \\
\text { Use }\end{array}$ & $\begin{array}{l}\text { MonsoonSIM provides an attractive learning } \\
\text { environment }\end{array}$ & \\
\hline ATU 3 & & Overall, I like using MonsoonSIM & (Ngai et al., 2007) \\
\hline BI 1 & Behavioral & $\begin{array}{l}\text { I intend to increase my use of MonsoonSIM in the } \\
\text { future }\end{array}$ & (Ngai et al., 2007) \\
\hline BI 2 & Intention & I intend to use MonsoonSIM to assist my learning & (Liaw, 2008) \\
\hline BI 3 & & I intend to use MonsoonSIM as a learning tool 4 & \\
\hline
\end{tabular}

\subsection{Validity Analysis}

All coefficients of the items were valid as the 2-tailed was less than 0.005. The Pearson correlation coefficient for perceived usefulness was 0.903 , perceived ease of use was 0.619 , perceived enjoyment was 0.843 , attitude to use was 0.932 , and behavioural intention to use was 0.829 . Hence, all items in the questionnaire were valid $(r>0.444)$.

\subsection{Reliability Analysis}

Based on the Cronbach's alphas, three items in attitude to use MonsoonSIM had excellent reliability (0.948). This was followed by 3 items in perceived usefulness (0.896), 4 items in perceived ease of use (0.835), and 4 items in perceived enjoyment $(0.826)$ which had good reliability. Finally, 3 items in behavioral intention to use MonsoonSIM (0.775) had acceptable reliability. Thus, all the items in the questionnaire were reliable.

\section{Research Findings}

\subsection{Demographic Analysis}

Of the 260 respondents, more than half were females (62.3\%), followed by males $(37.7 \%)$. Table 2 describes the respondents based on their faculties. 
Table 2. Respondents' faculty

\begin{tabular}{rcc}
\hline & Frequency & Percent \\
\hline Valid FKM & 28 & 10.8 \\
FKE & 7 & 2.7 \\
FC & 6 & 2.3 \\
FM & 153 & 58.8 \\
FGHT & 24 & 9.2 \\
FS & 7 & 2.7 \\
FAB & 9 & 3.5 \\
FBME & 21 & 8.1 \\
Other & 5 & 1.9 \\
Total & 260 & 100.0
\end{tabular}

In terms of year of study, more than half of the respondents (138 respondents) were fourth year students (53.1\%), followed by 51 third year students (19.6\%), 49 second year students (18.8\%), 17 from fifth year students $(6.5 \%)$, and the remaining 5 first year students $(1.9 \%)$. Table 3 describes the frequencies at which the respondents played MonsoonSIM.

Table 3. Frequencies of playing MonsoonSIM

\begin{tabular}{rc}
\hline & Frequency \\
\hline Valid ONCE & 105 \\
$2-5$ TIMES & 88 \\
6-10 TIMES & 36 \\
MORE THAN 10 & 31 \\
Total & 260 \\
\hline
\end{tabular}

\subsection{Technology Acceptance Analysis}

Table 4 summarizes the average mean scores for all variables. Table 4 shows the mean scores for each element (for more details, see Appendix A). The means for all veriables were high, i.e. they were more than 3.68 (Ghani et al., 2014), except for perceived ease of use which had a moderate mean. This showed that the students perceived MonsoonSIM to be a good business simulation game as they felt that it was useful and fun to use it. Thus, the students had the intention to continue using it in the future.

Table 4. Average score for each variable 


\begin{tabular}{lll}
\hline No & Variables & Average Mean \\
\hline 1 & Perceived Usefulness & 3.98 \\
2 & Perceived Ease of Use & 3.46 \\
3 & Perceived Enjoyment & 4.17 \\
4 & Attitude to Use MonsoonSIM & 4.21 \\
5 & Behavioral Intention to Use MonsoonSIM & 3.86 \\
\hline
\end{tabular}

\subsection{Relationship Between Perceived Usefulness and Attitude to Use MonsoonSIM}

Based on Table 5, perceived usefulness had a positive relationship with attitude to use MonsoonSIM. Since the r-value was 0.661 , the strength of this relationship was moderate. The relationship was significant because the p-value was less than 0.01 .

\subsection{Relationship Between Perceived Usefulness and Behavioral Intention to Use MonsoonSIM}

Based on Table 5, perceived usefulness had a positive relationship with behavioral intention to use MonsoonSIM, and this was significant because the p-value was less than 0.01 . The strength of this relationship was moderate because the r-value was 0.597 .

\subsection{Relationship Between Perceived Ease of Use and Attitude to Use MonsoonSIM}

Table 5 also shows that perceived ease of use had a positive relationship with attitude to use MonsoonSIM. The strength of this relationship was weak as the r-value was 0.278. The relationship was significant because the p-value was less than 0.01 .

\subsection{Relationship Between Perceived Enjoyment and Attitude to Use MonsoonSIM}

Table 5 also shows that perceived enjoyment had a positive relationship with attitude to use MonsoonSIM. The relationship was significant because the p-value was less than 0.01 . The r-value was 0.796 , so the relationship was strong.

\subsection{Relationship Between Perceived Enjoyment and Behavioral Intention to Use MonsoonSIM}

Based on Table 5, perceived enjoyment had a positive relationship with behavioral intention to use MonsoonSIM. The relationship was significant because the p-value was less than 0.01 . The r-value was 0.569 , thus this was a moderate relationship.

\subsection{Relationship Between Attitude to Use MonsoonSIM and Behavioral Intention to Use} MonsoonSIM

Table 5 shows that the attitude to use MonsoonSIM had a positive relationship with behavioral intention to use MonsoonSIM. This relationship was significant because the $\mathrm{p}$-value was less than 0.01 . The strength of this relationship was moderate because the r-value was 0.658 


\section{Macrothink}

Table 5. Pearson correlation analysis

\begin{tabular}{lll}
\hline Item & Pearson Correlation & Sig. (2-tailed) \\
\hline PU and ATU & $.661^{* *}$ & .000 \\
PU and BI & $.597^{* *}$ & .000 \\
PEOU and ATU & $.278^{* *}$ & .000 \\
PE and ATU & $.796^{* *}$ & .000 \\
PE and BI & $.569^{* *}$ & .000 \\
ATU and BI & $.658^{* *}$ & .000
\end{tabular}

$$
\begin{gathered}
\text { LEGEND } \\
\text { PU }=\text { Perceived Usefulness } \\
\text { PEOU }=\text { Perceived Ease of Use } \\
\text { PE }=\text { Perceived Enjoyment } \\
\text { ATU = Attitude to Use MonsoonSIM } \\
\text { BI = Behavioural Intention to Use MonsoonSIM }
\end{gathered}
$$

4.9 Association of Perceived Usefulness, Perceived Ease of Use, and Perceived Enjoyment AND Attitude to Use MonsoonSIM

This analysis was conducted to evaluate in more detail the relationship between the independent variables (perceived usefulness, perceived ease of use, and perceived enjoyment) and the dependent variable (attitude to use MonsoonSIM), apart from identifying the elements of the technology acceptance model that had the strongest influence on the students' attitude to use MonsoonSIM.

Table 6 shows the r-value of the said relationship was 0.817 . This meant that $81.70 \%$ of the users' ttitude to use MonsoonSIM could be predicted by perceived usefulness, perceived ease of use, and perceived enjoyment. Also, the $\mathrm{R}^{2}$-value was 0.667 , which meant that $66.70 \%$ of the variations in the users' attitude to use MonsoonSIM was influenced by the independent variables. 
Table 6. Summary of multiple regressions of study model

\begin{tabular}{|c|c|c|c|c|}
\hline Model & $\mathbf{R}$ & R square & Adjusted R Square & $\begin{array}{l}\text { Std. Error of the } \\
\text { estimate }\end{array}$ \\
\hline 1 & .817 & .667 & .664 & .40364 \\
\hline
\end{tabular}

Table 7 describes the beta-values of each independent variable based on their unstandardized coefficients. The largest beta-value was seen in perceived enjoyment $(\beta=0.667)$, followed by perceived usefulness $(\beta=0.251)$, and perceived ease of use $(\beta=0.002)$. Perceived usefulness and perceived enjoyment were significant as the p-values were less than 0.005 while perceived ease of use was not significant because the p-value was exceeded 0.005 .

Table 7. Results of multiple regression analyses

\begin{tabular}{|c|c|c|c|c|c|}
\hline \multirow{2}{*}{ Model } & \multicolumn{2}{|c|}{ Unstandardized Coefficients } & \multirow{2}{*}{$\begin{array}{l}\text { Standardized Coefficients } \\
\text { Beta }\end{array}$} & \multirow{2}{*}{$\mathbf{t}$} & \multirow{2}{*}{ Sig. } \\
\hline & $\mathrm{B}$ & Std. Error & & & \\
\hline 1 (Constant) & .426 & .188 & & 2.270 & .024 \\
\hline PUAV & .251 & .050 & .244 & 4.992 & .000 \\
\hline PEOUAV & .002 & .041 & .002 & .042 & .966 \\
\hline PENJOYAN & .667 & .050 & .636 & 13.234 & .000 \\
\hline
\end{tabular}

a. Dependent variable: ATUAV.

The unstandardized coefficients could also be explained in other way. A value of 0.667 meant that for each unit of increase in perceived enjoyment, there was a 0.667 unit increase in the players' attitude to use MonsoonSIM. Next, a value of 0.251 meant that for each unit of increase of perceived usefulness, there was a 0.251 unit increase in the players' attitude to use MonsoonSIM.

In conclusion, the element of the technology acceptance model that had the strongest influence on the users' attitude to use MonsoonSIM was perceived enjoyment, followed by perceived usefulness.

\section{Conclusion and Recommendations}

5.1 Research Objective (RO)1: To Investigate the Relationship Between Perceived Usefulness and Attitude to Use MonsoonSIM

Research objective 1 was achieved as the relationship between perceived usefulness and attitude to use MonsoonSIM was found to be positive and significant. This showed the research hypothesis 1 was supported. In more detail, it was a moderate positive relationship as the r-value was 0.661 and $p$-value was less than 0.01 . The finding of this study was in line with previous studies (Lee et al., 2005; Ngai et al., 2007; Park, 2009), thereby suggesting that 
students perceived a system to be one of the useful learning tools if it improve their learning. However, this study found disparate results with a previous study (Al-Adwan et al., 2013) as the fact was that students in Jordan were willing to adopt a system, but its beneficial effects had to be taken into consideration. Thus, after using MonsoonSIM, the students perceived it to be a good learning system as it could improve their learning performance.

\subsection{RO2: To Identify the Relationship Between Perceived Usefulness and Behavioral Intention to Use MonsoonSIM}

The results for research hypothesis 2 were also consistent with the results of other previous studies (Amoako-Gyampah, 2007; Davis et al., 1989; Lee et al., 2005; Ngai et al., 2007), because the relationship between perceived usefulness and behavioral intention to use the system was positive and significant. Hence, research objective 2 was achieved. In spite of the consistency of the results with those of previous studies, there was also disagreement with those of a previous study (Park, 2009). This was probably because university students in Korea already knew the benefits of the system since they have learned these during their high school days. Hence, perceived usefulness did not have a significant relationship with behavioral intention to use the system in Korea. Thus, this study could conclude that perceived usefulness had a positive effect on the behavioral intention to use MonsoonSIM as the students did not know the benefits of MonsoonSIM until they have used it.

\subsection{RO3: To Investigate the Relationship Between Perceived Ease of Use and Attitude to Use} MonsoonSIM

Research objective 3 was achieved as the results showed the positive and significant relationship between perceived ease of use and attitude to use MonsoonSIM ( $r=0.278 ; p<$ 0.01 ), so research hypothesis 3 was directly supported. The findings were in favor of the results of previous studies (Al-Adwan et al., 2013; Ngai et al., 2007; Park, 2009), whereby perceived ease of use significantly influenced attitude to use MonsoonSIM. However, the results of this study showed a weak positive relationship. This could be due to the fact that some of the respondents felt that the ERP systems which were used in MonsoonSIM were complicated (Hwang \& Cruthirds, 2017). Hence, this phenomenon had an affect on the students' attitude to use MonsoonSIM.

5.4 RO4: To Identify the Relationship Between Perceived Enjoyment and Attitude to Use MonsoonSIM

Research hypothesis 4 was supported and significant because the r-value was 0.796 and p-value was less than 0.01 . Thus, research objective 4 was achieved. The results were generally similar to those of previous studies (Dickinger et al., 2008; Van der Heijden, 2003), whereby perceived enjoyment exerted a strong impact on the system usage attitudes. As with Van der Heijden (2003), the effect of perceived enjoyment on attitude to use was almost similar to the effect of usefulness. Moreover, the portals that have been used in the study contained enjoyable functionality. Therefore, perceived enjoyment was considered to be an important element. The portal was similar to that of MonsoonSIM, in which entertainment had a significant impact on the users' attitude to use. Thus, the students perceived 
MonsoonSIM to be an enjoyable learning system.

\subsection{RO5: To Investigate the Relationship Between Perceived Enjoyment and Behavioral Intention to Use MonsoonSIM}

Next, research objective 5 was achieved because research hypothesis 5 was supported and significant. In agreement with previous studies (Dickinger et al., 2008; Lee et al., 2005), the results further suggested that perceived enjoyment had a strong effect on behavioral intention to use. Both studies agreed that any technology that is meant for young people should include an enjoyable function to motivate the users to use it. This suggestion could be related to the MonsoonSIM system as its target market comprised university or high school students. It has also successfully included the enjoyment function because many respondents in this study (i.e. UTM students) agreed that the usage of this system was enjoyable, apart from making time pass quickly. This was also seen in Chang et al. (2003), whereby half of the respondents reported that the business game was interesting. This study has proven that there was another important element (other than perceived usefulness and attitude to use) that influenced the behavioral intention to use.

\subsection{RO6: To Identify the Relationship Between Attitude to Use MonsoonSIM and Behavioral Intention to Use MonsoonSIM}

The r-value of the relationship between attitude to use towards behavioral intention to use was 0.658 . Hence, hypothesis 6 was supported and the research objective 6 was achieved. The relationship was significant because the p-value was less than 0.01 . The result was consistent with the results of previous studies (Dickinger et al., 2008; Lee et al., 2005; Ngai et al., 2007). Some studies have dropped the attitude to use variable as it did not give significant results towards the behavioral intention to use (Venkatesh \& Bala, 2008; Venkatesh \& Davis, 2000) but there are some studies take this variable as an important in giving an impact towards behavioral intention to use. For example, Park (2009) stated that the intentions of Korean students to use e-learning were affected by their attitudes and not by perceived usefulness or perceived ease of use. This was because online learning is considered to be easy nowadays, and that the said students already knew the benefits of e-learning. Thus, the users had an intention to use the system or technology if they had positive feelings (attitudes) towards it (Dickinger et al., 2008). It could be concluded that the respondents had a positive perceptions that originated from perceived usefulness and perceived enjoyment; these led to their intentions to use MonsoonSIM. Thus, attitude to use was an important element in this study as it had an influence on the behavioral intentions to use MonsoonSIM.

\subsection{RO7: To Determine the Elements of the Technology Acceptance Model that Had the Strongest Influence on the Students'Attitude to Use MonsoonSIM}

Research objective 7 was achieved as perceived enjoyment has the highest beta-value ( $\beta=$ 0.667 ), followed by perceived usefulness and perceived ease of use. The findings of this study were in line with those of a previous study (Lee et al., 2005), in which perceived enjoyment (rather than perceived usefulness and perceived ease of use) had the strongest influence on the attitude to use. However, this study did not concur with Park (2009) who 
reported that perceived usefulness had the greatest impact on attitude to use. Our study also did not concur with (Ngai et al., 2007), who posited that perceived ease of use had the strongest effect on the usage attitudes. The associations of perceived enjoyment and usefulness with attitude to use MonsoonSIM was significant as the p-value was less than 0.05 , but that of perceived ease of use and attitudes was not significant ( $p>0.05)$. In conclusion, most of the students had positive feelings which originated from the enjoyment during the usage of MonsoonSIM business simulation. Hence, perceived enjoyment was the strongest determinant of a student's attitude to use MonsoonSIM.

\subsection{Implications of Study}

In this study, the findings suggest that MonsoonSIM developers must consider the factors that motivate the users to use this technology, which are perceived usefulness, perceived ease of use, perceived enjoyment, and attitude to use. These factors are included in the customers' perspectives, which in turn are one of the external factors that should be considered by the developers during the development of new technologies. Doing so can increase the intentions of the users to use MonsoonSIM.

Other than that, this study has an implication on tertiary education. Business simulation games which are utilised as educational tools can bring advantages if they have factors like perceived usefulness, perceived ease of use, and perceived enjoyment. In addition, perceived enjoyment is the most important determinant of attitude to use. The said results can help this institution to realize the importance of enjoyment in new systems of learning. Even though a system might be difficult to be learned or understood by first-time users, the students will still be willing to use it as long as the students feel the enjoyment. For instance, the enjoyment factor can be in the form of computer usage. The younger generation is more likely to use computers in their learning sessions. Hence, MonsoonSIM has a high level of perceived enjoyment as it uses computers to teach enterprise resource management. By using computers, students will have positive perceptions and hence, accept the new system of learning. Thus, it is important to use computers as much as possible to motivate students to learn and accept a new system of learning.

\subsection{Limitations}

There were several limitations in this study. First, the data was only collected once. Usually, for studies which look at the users' acceptance of technology, data needs to be collected several times (for example, at one month, three months, and six months) to obtain more accurate results (Venkatesh \& Bala, 2008). The reason for not collecting the data more than once was due to time constraints. In other words, we did not conduct a longitudinal study because of time constraints.

Second, this study only had a small sample scope (i.e. students only). There were many other aspects that could have influence the usage of business simulation games, such as lecturers or teachers, top management of the university, and others. Without permission from the lecturers or top management of university, the students would not have been able to experience this kind of simulation.

Other than that, this study did not include social factors (e.g. subjective norms) as a variable 
in the model. This variable was crucial and important in previous studies (Park, 2009). Had this variable been included, there could be some changes in the results. For example, changes in the ranks of the relationships between the independent variables and attitude to use MoosoonSIM.

Lastly, the scope of the study was limited to Universiti Teknologi Malaysia, Skudai. Even though many other students from other universities have used MonsoonSIM, the researchers could not obtain all the information from other universities due to time constraints. Hence, the results were less accurate because they were based on one university only.

\subsection{Recommendations for Future Researches}

First, future studies should include other variables that can impact the students' acceptance of MonsoonSIM. For example, social factors such as subjective norms and social influence could have been crucial in this model. This was because the model that was used in this study was adapted from a previous study (Lee et al., 2005), whereby only about $35 \%$ of the variances were explained by this model. Next, future researches can include other universities that have adopted MonsoonSIM because different cultures can have an influence on the results of the study (Cronan \& Douglas, 2012). Other than that, future studies can also investigate the factors that affect the teachers or lecturers to use MonsoonSIM. If the teachers or lecturers are against the usage of MonsoonSIM, students will not have a chance to play with and learn from MonsoonSIM. Thus, it is important to identify the variables that can motivate the teachers or lecturers to use and accept it. Finally, and most importantly, longitudinal approaches should be used in this type of study. Results from longitudinal studies may be more accurate, so future researchers can determine precisely the factors that determine the usage of MonsoonSIM by the students.

\section{Conclusion}

In conclusion, this study has come up with a clear yet simple model that can be used to investigate the factors of the users to use business simulation games. Even though there were several limitations in this study, all the objectives have still been achieved. It is concluded that perceived usefulness, perceived ease of use, and perceived enjoyment had a positive relationship with attitude to use MonsoonSIM. Also, perceived usefulness, perceived enjoyment, and attitude to use MonsoonSIM had a positive relationship with behavioral intention to use MonsoonSIM. Perceived ease of use had positive relationships with perceived usefulness and perceived enjoyment. Finally, perceived enjoyment was the strongest determinant of attitude to use MonsoonSIM.

\section{Acknowledgement}

Funding for this project was received from the Malaysian Ministry of Higher Education and Universiti Teknologi Malaysia under the research grant (Vot. 13J52).

\section{References}

Al-Adwan, A., Al-Adwan, A., \& Smedley, J. (2013). Exploring students' acceptance of e-learning using Technology Acceptance Model in Jordanian universities. International 
Journal of Education and Development using Information and Communication Technology, 9(2), 4-18. Retrieved from https://files.eric.ed.gov/fulltext/EJ1071365.pdf

Amoako-Gyampah, K. (2007). Perceived usefulness, user involvement and behavioral intention: an empirical study of ERP implementation. Computers in Human Behavior, 23(3), 1232-1248. https://doi.org/10.1016/j.chb.2004.12.002

Chang, J., Lee, M., Ng, K.-L., \& Moon, K.-L. (2003). Business simulation games: the Hong Kong experience. Simulation \& Gaming, 34(3), 367-376. https://doi.org/10.1177/1046878103255877

Cronan, T. P., \& Douglas, D. E. (2012). A student ERP simulation game: A longitudinal study. Journal of Computer Information Systems, $53 \quad$ (1), 3-13. http://dx.doi.org/10.1080/08874417.2012.11645591

Davis, F. D., Bagozzi, R. P., \& Warshaw, P. R. (1989). User acceptance of computer technology: a comparison of two theoretical models. Management Science, 35(8), 982-1003. https://doi.org/10.1287/mnsc.35.8.98

Davis, F. D., Bagozzi, R. P., \& Warshaw, P. R. (1992). Extrinsic and intrinsic motivation to use computers in the workplace. Journal of Applied Social Psychology, 22(14), 1111-1132. https://doi.org/10.1111/j.1559-1816.1992.tb00945.x

Dickinger, A., Arami, M., \& Meyer, D. (2008). The role of perceived enjoyment and social norm in the adoption of technology with network externalities. European Journal of Information Systems, 17(1), 4-11. https://doi.org/10.1057/palgrave.ejis.3000726

Faria, A. J. (1998). Business simulation games: Current usage levels - an update. Simulation \& Gaming, 29(3), 295-308. https://doi.org/10.1177/1046878198293002

Fishbein, M (1967). Readings in attitude theory and measurement. Oxford, England: Wiley.

Fishbein, M., \& Ajzen, I (1975). Belief, attitude, intention and behavior: an introduction to theory and research. MA: Addison-Wesley.

Ghani, M. Z., Ahmad, A. C., \& Ibrahim, S. (2014). Stress among special education teachers in Malaysia. Procedia - Social and Behavioral Sciences, 114, 4-13. https://doi.org/10.1016/j.sbspro.2013.12.648

Holden, R. J., \& Karsh, B.-T. (2010). The technology acceptance model: Its past and its future in health care. Journal of Biomedical Informatics, 43(1), 159-172. https://doi.org/10.1016/j.jbi.2009.07.002

Hwang, M., \& Cruthirds, K. (2017). Impact of an ERP simulation game on online learning.

The International Journal of Management Education, 15(1), 60-66. https://doi.org/10.1016/j.ijme.2017.01.004

Krejcie, R. V., \& Morgan, D. W. (1970). Determining sample size for research activities. Educational and Psychological Measurement. 30(3), 607-610. https://doi.org/10.1177/001316447003000308 
Kumar, M., Talib, S. A., \& Ramayah, T. (2013). Business research methods, Oxford Fajar Oxford University Press.

Lee, M. K., Cheung, C. M., \& Chen, Z. (2005). Acceptance of internet-based learning medium: the role of extrinsic and intrinsic motivation. Information \& Management, 42(8), https://doi.org/10.1016/j.im.2003.10.007

Ngai, E. W., Poon, J., \& Chan, Y. (2007). Empirical examination of the adoption of WebCT using TAM. Computers \& education, 48(2), 250-267. https://doi.org/10.1016/j.compedu.2004.11.007

Park, S. Y. (2009). An analysis of the technology acceptance model in understanding university students' behavioral intention to use e-learning. Educational Technology \& Society, 12 (3), 150-162. Retrieved from https://www.j-ets.net/ETS/journals/12_3/14.pdf

Pikkarainen, T., Pikkarainen, K., Karjaluoto, H., \& Pahnila, S. (2004). Consumer acceptance of online banking: an extension of the technology acceptance model. Internet Research, 14(3), 224-235. https://doi.org/10.1108/10662240410542652

Roca, J. C., Chiu, C.-M., \& Martínez, F. J. (2006). Understanding e-learning continuance intention: An extension of the Technology Acceptance Model. International Journal of Human-Computer Studies, 64(8), 683-696. https://doi.org/10.1016/j.ijhcs.2006.01.003

Saunders, M. N. K., Lewis, P., \& Thornhill, A. (2012). Research methods for business students, Pearson Education Limited.

Tao, Y.-H., Cheng, C.-J., \& Sun, S.-Y. (2009). What influences college students to continue using business simulation games? The Taiwan experience. Computers \& Education, 53(3), 929-939. https://doi.org/10.1016/j.compedu.2009.05.009

Tao, Y.-H., Cheng, C.-J., \& Sun, S.-Y. (2012). Alignment of teacher and student perceptions on the continued use of business simulation games. Educational Technology \& Society, 15(3), 177-189. Retrieved from https://www.j-ets.net/ETS/journals/15_3/13.pdf

Van Der Heijden, H. (2003). Factors influencing the usage of websites: the case of a generic portal in The Netherlands. Information \& Management, 40(6), 541-549. https://doi.org/10.1016/S0378-7206(02)00079-4

Venkatesh, V., \& Bala, H. (2008). Technology acceptance model 3 and a research agenda on interventions. Decision $\quad$ Sciences, 273-315. https://doi.org/10.1111/j.1540-5915.2008.00192.x

Venkatesh, V., \& Davis, F. D. (2000). A theoretical extension of the technology acceptance model: Four longitudinal field studies. Management Science, 46(2), 186-204. https://doi.org/10.1287/mnsc.46.2.186.11926

Wawer, M., Milosz, M., Muryjas, P., \& Rzemieniak, M. (2010). Business simulation games in forming students' entrepreneurship. International Journal of Euro-Mediterranean Studies, 3, 49-71. Retrieved from http://www.emuni.si/press/ISSN/1855-3362/3_049-071.pdf 


\section{Macrothink}

International Journal of Learning and Development

ISSN 2164-4063 2018, Vol. 8, No. 2

Wu, J.-H., \& Wang, S.-C. (2005). What drives mobile commerce?: An empirical evaluation of the revised technology acceptance model. Information \& management, 42(5), 719-729. https://doi.org/10.1016/j.im.2004.07.001

\section{Appendix A}

Table 4. Detail Means for Each Element

\begin{tabular}{llc}
\hline No & Items & Mean \\
\hline 1 & Perceived Usefulness & 3.85 \\
& $\circ \quad$ Using MonsoonSIM improves my learning performance. \\
& $\circ \quad \begin{array}{l}\text { Having MonsoonSIM in the curriculum, it enables me to learn more } \\
\quad \text { efficiently. }\end{array}$ \\
& $\circ \quad$ I believe MonsoonSIM contents are useful. & 4.17
\end{tabular}

2 Perceived Ease of Use

○ Interacting with MonsoonSIM does not require a lot of my mental effort. $\quad 3.02$

○ Learning to operate a MonsoonSIM system is easy for me. 3.52

○ It will be difficult to learn how to use MonsoonSIM. 3.59

○ Overall, I believe that MonsoonSIM is easy to use. 3.71

$3 \quad$ Perceived Enjoyment

○ Times flies very quickly when I use MonsoonSIM. 4.12

○ It is interesting to use MonsoonSIM.

○ I feel like exploring more information when I use MonsoonSIM. 4.11

○ I would have fun using MonsoonSIM.

$4 \quad$ Attitude to Use MonsoonSIM

○ Times flies very quickly when I use MonsoonSIM. 4.23

○ It is interesting to use MonsoonSIM.

○ I feel like exploring more information when I use MonsoonSIM. 4.13

$5 \quad$ Behavioral Intention to Use MonsoonSIM

O I intend to increase my use of MonsoonSIM in the future. 3.89

○ I intend to use MonsoonSIM to assist my learning. 3.82

○ I intend to use MonsoonSIM as a learning tool. 3.86 


\section{Macrothink}

International Journal of Learning and Development

ISSN 2164-4063

\section{Copyright Disclaimer}

Copyright for this article is retained by the author(s), with first publication rights granted to the journal.

This is an open-access article distributed under the terms and conditions of the Creative Commons Attribution license (http://creativecommons.org/licenses/by/4.0/). 